\title{
A functional task exercise programme was better than a resistance exercise programme in elderly women
}

de Vreede PL, Samson MM, van Meeteren NL, et al. Functional-task exercise versus resistance strength exercise to improve daily

function in older women: a randomized, controlled trial. J Am Geriatr Soc 2005;53:2-10.

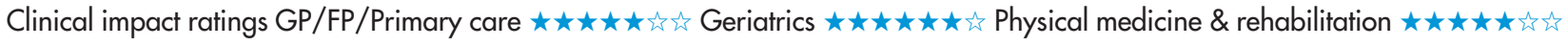

In elderly community dwelling women, is a functional task exercise programme (FTP) better than a resistance exercise programme (REP) for improving activities of daily living?

\section{METHODS}

$\square$

Design: randomised controlled trial

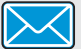

Allocation: $\left\{\right.$ allocation concealed. $\left.{ }^{*}\right\} \dagger$

Blinding: blinded (data collectors).*

Follow up period: 12 weeks.

Setting: community leisure centre in Utrecht, the Netherlands.

0. Patients: 98 elderly women $\geqslant 70$ years of age (mean age $74 \mathrm{y}$ ) who were medically fit to participate in an exercise programme. Exclusion criteria included recent fractures, unstable cardiovascular or metabolic diseases, and musculoskeletal disease or other chronic illness that might limit training or testing.

R.

Intervention: (i) FTP (core exercises done for $>2$ of 4 domains [moving with a vertical or horizontal component, carrying an object, and changing between lying-sitting-standing position] in 3 sessions of 5-10 repetitions) ( $n=33$ ), (ii) REP (exercises to strengthen the muscle groups that are important for daily task performance in 3 sets of 10 repetitions) ( $n=34$ ), or (iii) control (normal pattern of activity) $(n=31)$. Exercises were done 3 times/ week (1 h sessions).

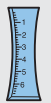

Outcomes: functional performance (Assessment of Daily Activity Performance [ADAP] and Timed Up and Go [TUG]) and muscle function (isometric knee extensor strength [IKES], isometric elbow flexor strength [IEFS], handgrip strength [HGS], and leg extension power [LEP]).

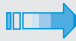

Patient follow up: $86 \%$

*See glossary.

†Information provided by author.

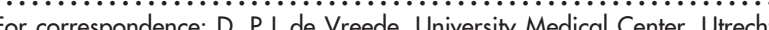
the Netherlands. p.l.devreede@freeler.nl

Source of funding: Zorg Onderzoek Nederland-Medische Wetenschappen.

\section{MAIN RESULTS}

Participants in the FTP had a greater increase in ADAP total score compared with those who received REP (table) or the control intervention $(\mathrm{p}<0.001)$. FTP and REP groups did not differ for TUG, HGS, or LEP (table). The REP and control groups did not differ for ADAP total score $(\mathrm{p}=0.06)$, TUG $(\mathrm{p}=1.00)$, or HGS $(\mathrm{p}=1.00)$. REP improved IKES and IEFS more than FTP (table).

\section{CONCLUSION}

In elderly community dwelling women, a functional task exercise programme was better than a resistance exercise programme for improving physical functional performance.

Commentary

U se it or lose it. Although geriatricians hear this mantra throughout their training, little evidence exists that prescribing an exercise programme focusing on functional tasks of everyday life has any advantage over the much more common practice of prescribing resistance exercises to improve strength and endurance. After a 12 week training programme in the study by de Vreede et al, the benefit of FTP for strength, balance, coordination, and ADAP persisted after 6 more months, whereas no persistent benefit was found in the REP group. In addition, participants randomised to the FTP group had fewer dropouts due to loss of interest and other causes than did the REP and non-exercise control groups.

de Vreede et al showed that the FTP group had a $>10 \%$ increase in ADAP, which is considered clinically significant. Although the reliability and validity of ADAP have not yet been published, it is closely patterned after the well validated Continuous-Scale Physical Functional Performance. This latter scale showed a similar magnitude of difference between functionally independent community dwelling elderly patients and the most independent residents of a long term care facility.

Although other studies have shown a functional benefit of task specific exercise, ${ }^{2}$ the study by de Vreede et al (which compared a similar regimen with resistance exercise) showed similar benefit for increasing strength but not for improving functional task performance. We should consider recommending functionally relevant exercise to our elderly patients.

Jay S Luxenberg, MD Jewish Home, San Francisco, California, USA 1 Cress ME, Buchner DM, Questad KA, et al. Arch Phys Med Rehabil 1996;77:1243-50

2 Alexander NB, Galecki AT, Grenier ML, et al. J Am Geriatr Soc 2001;49:1418-27.

Functional task exercise programme (FTP) $v$ resistance exercise programme (REP) for improving physical and muscle function*

\begin{tabular}{|c|c|c|c|c|c|}
\hline \multirow[b]{2}{*}{ Outcomes at 3 months } & \multicolumn{3}{|c|}{ Mean change from baseline } & \multirow{2}{*}{$\begin{array}{l}\text { Difference in mean change from } \\
\text { baseline between FTP and REP }(95 \% \mathrm{Cl})\end{array}$} & \multirow[b]{2}{*}{ p Value } \\
\hline & FTP & REP & Control & & \\
\hline Assessment of Daily Activity Performance total & 6.8 & 3.2 & 0.3 & $3.6(1$ to 6$)$ & 0.007 \\
\hline Timed Up and Go (sec) & -0.1 & -0.1 & 0.1 & $0(-0.4$ to 0.4$)$ & $1.00 \dagger$ \\
\hline Isometric knee extensor & -7.0 & 23.7 & -8.2 & 30.7 (16 to 45$)$ & 0.001 \\
\hline Hand grip strength & -0.1 & -0.2 & -0.3 & $0.1(-0.7$ to 0.9$)$ & $1.00 \dagger$ \\
\hline Isometric elbow flexor strength & -1.0 & 10.6 & 0.0 & $11.6(2.8$ to 20$)$ & 0.03 \\
\hline Leg extension power & 11.2 & 10.8 & -7.0 & $0.4(-14$ to 14$)$ & $1.000 \dagger$ \\
\hline
\end{tabular}

${ }^{*} \mathrm{Cl}$ defined in glossary. Difference in mean change from baseline and $\mathrm{Cl}$ calculated from data in article. $†$ Not significant. 